\title{
Thermo-Physical, Mechanical and Hygro-Thermal Properties of Newly Produced Aerated Concrete
}

\author{
Adelaïde Lareba OUEDRAOGO ${ }^{1} \cdot$ Adamah MESSAN $^{2}$. Etienne MALBILA ${ }^{1,3}$. Emmanuel \\ OUEDRAOGO ${ }^{1}$. Dieudonné Joseph BATHIEBO ${ }^{1}$. Florent pèlèga KIENO ${ }^{1}$ · Philippe BLANCHART ${ }^{4}$
}

\author{
'Laboratoire d'Energies Thermiques Renouvelables (L.E.T.RE)-Université Joseph KI-ZERBO, UFR / SEA-03 BP 7021 Ouagadougou, \\ Burkina Faso. \\ ${ }^{2}$ Laboratoire Eco Matériaux et Habitats Durables 2iE, 01 BP594 Ouagadougou 01, Burkina Faso. \\ ${ }^{3}$ Université de Fada N'Gourma, BP 54 Fada, Burkina Faso. \\ ${ }^{4}$ Institut de Recherche sur la Céramique (IRCER), Limoge -France.
}

\section{ABSTRACT}

The main objective of this study is to characterize a material, non-autoclaved aerated concrete, referred to as "foamed concrete", newly produced in Burkina Faso. This study made it possible to determine some thermo-physical, mechanical and hygro-thermal properties of foamed concrete. The material was obtained by making a mixture of cement, sand, water and a foaming agent.The tests were carried out with five types of samples having densities between 600 and $930 \mathrm{~kg} / \mathrm{m}^{3}$ and a water content ranging from 22 to $35 \%$. The experimental results obtained show that the studied foamed concrete has a thermal conductivity ranging from 0.05 to $0.2 \mathrm{~W} / \mathrm{m} . \mathrm{K}$ and compressive strength is between 1.2 to $3.4 \mathrm{MPa}$. The dynamic Young's modulus is between 1.18 and $3.1 \mathrm{GPa}$ and the porosity is varying from 55.60 to $72.36 \%$. Analysis of the results show that the incorporation of the foam in the mortar made it possible to have a more insulating material and acceptable mechanical properties for sustainable construction.

(c) 2021 JMSSE · INSCIENCEIN. All rights reserved

\section{ARTICLE HISTORY}

Received 07-07-2021

Revised 28-08-2021

Accepted 30-08-2021

Published 21-10-2021

\section{KEYWORDS}

Foamed Concrete Thermo-Physical \& Mechanical Properties Local Materials Sustainable-

Construction

\section{Introduction}

In the construction of cement masonry buildings, the weight of the concrete is a very large proportion of the total load on the structure. This leads to large parts of infrastructure and very heavy loads to be transmitted to the supporting soils. In addition, being one of the most used materials in construction because of its mechanical properties, it has poor thermal properties. In Burkina Faso, the construction of building envelopes (with cement block) is gaining in importance because of its high mechanical resistance. Modern constructions incorporating concrete as building materials with high energy consumption are very widespread. This leads users to use other very expensive devices (fans, air conditioning, etc.) to achieve thermal comfort. Given the limited load-bearing capacities of the soil and to have medium-sized structures and moderate loads on the ground, it is necessary to use suitable materials, in particular lighter and insulating concrete such as foamed concrete (FC).

Foamed concrete is a lightweight material that is easy to handle when constructing buildings unlike heavy concrete. Its construction is fast, solid, stable and resists over time. It is easy to use, durable and "weighs less" on the environment. The quality of foamed concrete depends on many factors such as the choice of the foaming agent, the foam production method, the material production method, the type of mixer, the mixing time and the mixing consistency [1-8]. A wide range of density (300-1600 $\mathrm{kg} / \mathrm{m}^{3}$ ) can be obtained and used for various applications.
The material is used for non-structural applications such as thermal insulation screeds, thermal and sound insulation of roofs and ceilings, filling of voids (insulation in hollow blocks or in any other empty space when the important insulating properties are expected), roof insulation, with a density between 200 and $500 \mathrm{~kg} / \mathrm{m}^{3}$, partition walls, and non-load bearing masonry blocks, thermal and sound insulation of multi-level residential building screeds for a mass density between 600 and $1000 \mathrm{~kg} / \mathrm{m}^{3}$, load-bearing panels for a density between 1200 and $1800 \mathrm{~kg} / \mathrm{m}^{3}[4,9$ 10].

The main idea of this study is to study the properties of foamed concrete with a density of less than $1000 \mathrm{~kg} / \mathrm{m}^{3}$ to obtain an optimized material. The material chosen must have at the same time a low density, good hydro-thermal properties, and an acceptable mechanical resistance to obtain an insulating and durable building.

\section{Experimental \\ Raw materials}

Foamed concrete is made up of cement, sand, foam and water. In this study, Portland cement (CEM II / A-M 42.5 R) from CIMFASO was used for the mixture. The aggregate used is natural siliceous sand from a sand pit in Manga with the following geographical coordinates: $11^{\circ} 39^{\prime} 48$ North latitude and $-1^{\circ} 4$ '23 West longitude. The foaming agent used is synthetic with a density of $30 \mathrm{~g} / \mathrm{l}$. It was supplied by the company ISOLTECH in France. 


\section{Formulation}

This formulation consists in designing different samples for physical, mechanical and thermal tests. The Table 1 shows the formulation of the different samples tested.

Table1 : Formulation of the tested materials

\begin{tabular}{|c|c|c|c|c|c|}
\hline $\begin{array}{l}\text { Density }(\mathrm{kg} / \mathrm{m} 3) \\
\text { formposition of }\end{array}$ & 600 & 650 & 730 & 830 & 930 \\
\hline $\mathrm{C} / \mathrm{C}$ & 1 & 1 & 1 & 1 & 1 \\
\hline $\mathrm{S} / \mathrm{C}$ & 0.4 & 0.4 & 0.4 & 0.4 & 0.4 \\
\hline $\mathrm{W} / \mathrm{C}$ & 0.6 & 0.6 & 0.6 & 0.6 & 0.6 \\
\hline $\mathrm{F} / \mathrm{C}$ & 0.048 & 0.0432 & 0.036 & 0.03 & 0.024 \\
\hline
\end{tabular}

C / C: Cement to cement mass ratio,

$\mathrm{S} / \mathrm{C}$ : Sand to cement mass ratio

W / C: Water to cement mass ratio,

F / C: Foam to cement mass ratio.

We varied the amount of the foam from 1.2 to $2.4 \%$ by mass in the mixture.

\section{Physico-mechanical and thermal characterization of foamed concrete specimens}

Total porosity

We used the air pycnometer method for specific density measurement after grinding the samples making them into powder form. The materials (samples) tested are crushed, ground, measured and put into the air pycnometer. The total porosity is the ratio between the difference in the specific density of the material and the bulk density by the specific density:

$$
\eta(\%)=\left[\left(\gamma_{s}-\gamma_{d}\right) / \gamma_{s}\right] * 100
$$

Where $\eta(\%)$ is the porosity in percentage, $\gamma_{s}$ the specific density of the material and $\gamma_{s}$ the bulk density of the material.

\section{Mechanical tests}

Figure 1 shows us the experimental device for testing compression, compressive strength (NF EN 13791) and Young's dynamic modulus (non-destructive test)

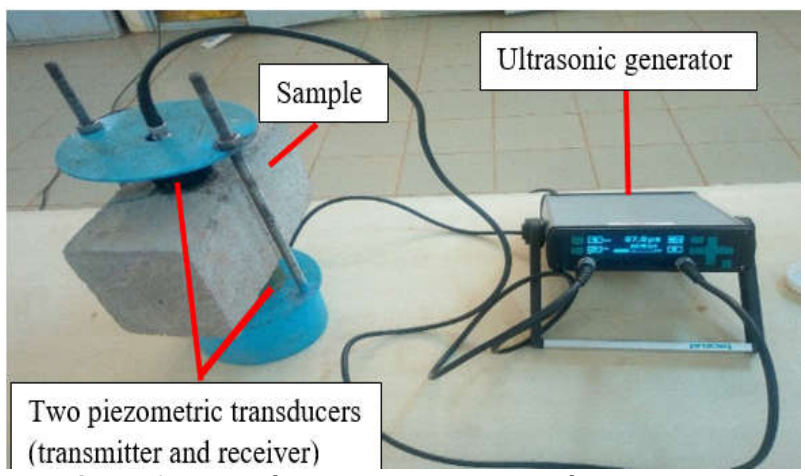

Figure 1: Material propagation wave speed measuring device (Pundit Lab Plus)

The compressive strength is determined on cubic specimens of dimension $10 \times 10 \times 10 \mathrm{~cm}^{3}$ using a hydraulic press.To perform the compression test, a computer-controlled static multi-test hydraulic press is used to crush the specimens of foamed concrete blocks after curing for 28 days.It has a maximum capacity of 300 $\mathrm{kN}$ in compression and a loading rate of $0.5 \mathrm{kN} / \mathrm{s}$ and a speed of $0.02 \mathrm{~mm} / \mathrm{s}$. The value of the compression is obtained by making the ratio of the maximum force on the surface of the section of the test piece. The compressive strength $\left(R_{c}\right.$ expressed in $\left.\mathrm{MPa}\right)$ is given by the following relation:

$$
R_{c}=F / S
$$

With $\mathrm{F}$ the maximum value of the applied force $(\mathrm{N})$ and $\mathrm{S}$ the area of the section of the test piece in $\left(\mathrm{mm}^{2}\right)$.

We performed Young Dynamic's modulus tests on rectangular specimens $20 \mathrm{~cm}$ long, $10 \mathrm{~cm}$ wide and $12.5 \mathrm{~cm}$ high. The device used for the measurement of the ultrasound speed is the PUNDIT Lab Plus (Portable Ultrasonic Non-Destructive Digital Indicating Tester) of FIG. 1. The dynamic Young's modulus of the various samples was determined using the method of Ultrasonic velocity based on the transmission of an ultrasonic wave in the samples (compacted granular medium) according to standard EN 12504-4.The measured speed is used in the calculation with a Poisson's ratio $v=(0.2)$,[9] according to equation 3 . Thus, the dynamic strain modulus $E_{D}$ is given by the following relation:

$$
\left.E_{D}=V^{2} * \rho *(1+v)(1-2 v) / 1-v\right)
$$

Where $E_{D}$ is the Dynamic Young's modulus (GPa), $\mathrm{V}$ is the wave propagation speed in (m /s), $\rho$ is the bulk density of the test piece $\left(\mathrm{kg} / \mathrm{m}^{3}\right)$ and $v$ is the Poisson's ratio.

\section{Thermal tests}

The thermal characterization of foamed concrete specimens consists in determining the parameters of thermal conductivity, thermal diffusivity and thermal effusivity. The device used to do this is that of DesProTherm commonly used on construction materials[11].

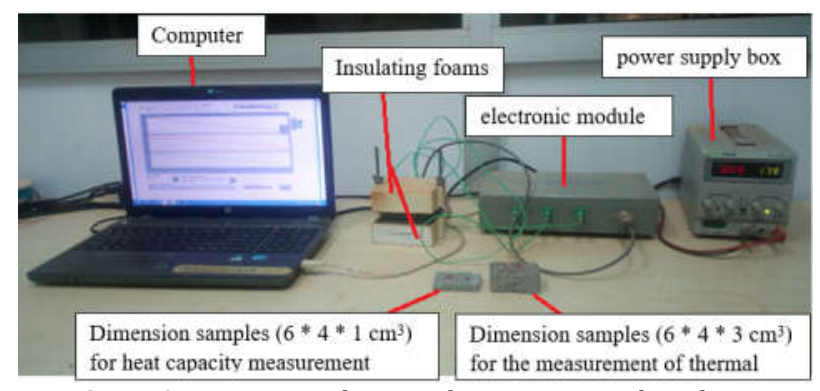

Figure 2: Experimental setup of an asymmetric hot plane (DesProTherm)

The thermal properties were determined by the asymmetric hot plane method used in the DesProTherm device (thermal properties estimator) according to figure 2. The thermal effusivity (E) was measured on samples of size $\left(6 \times 4 \times 3 \mathrm{~cm}^{3}\right)$. These dimensions made it possible to completely cover the measuring cell and prevent the flow of heat from passing through the sample to be tested. In addition, specific heat capacity $(\mathrm{Cp})$ measurements were performed on samples $\left(6 \times 4 \times 1 \mathrm{~cm}^{3}\right)$, where the heat flow passes through the thickness of the material. Once these two parameters are obtained, thermal conductivity and thermal diffusivity are determined using equations 4 and 5, respectively. If the thermal effusivity (E) and the thermal capacity (Cp) of the material are known, the thermal 
conductivity and thermal diffusivity are deduced from the relationship expressed respectively by the following equations (4) and (5):

$$
\begin{aligned}
& \lambda=E^{2} /\left(\rho * C_{P}\right) \\
& \alpha=\lambda /\left(\rho * C_{P}\right)
\end{aligned}
$$

Where $\boldsymbol{\alpha}$ is the thermal diffusivity (in $\mathrm{m}^{2} / \mathrm{s}$ ), $\lambda$ the thermal conductivity of the material (in $\mathrm{W} \mathrm{m}^{-1} \mathrm{~K}^{-1}$ ), $\rho$ the density of the material (in $\mathrm{Kg} \mathrm{m}^{-3}$ ), $\mathrm{C}_{\mathrm{p}}$ the specific heat capacity of the material (in J Kg-1 $\mathrm{K}^{-1}$ ), $E$ thermal effusivity (in $\left(\mathrm{J} \mathrm{K}^{-1} \mathrm{~m}^{-2} \mathrm{~S}^{-}\right.$ $1 / 2$ ).

\section{Water content}

The material is first oven dried at $40{ }^{\circ} \mathrm{C}$ until a mass change of less than $0.1 \%$ is achieved. It is then immersed in water until it has a constant mass before carrying out the tests. It is left in water until it reaches its maximum value corresponding to a state of saturation. The air contained in the foamed concrete is replaced by water.

$$
w=\left[\left(m_{h}-m_{s}\right) / m_{s}\right] * 100
$$

Where $\mathbf{w}$ is the water content (\%), $m_{h}$ the mass of the wet sample (in g) $m_{s}$ the mass of the dried sample (in g).

\section{Results and Discussion \\ Characteristics of the aggregate}

The particle size analysis carried out on the sand made it possible to determine the different sizes and the percentage of grains. The percentages obtained are used in the form of a graph (particle size analysis curve).The results obtained by the sieving of the aggregates are represented in the form of a plot on a particle size diagram comprising on the abscissa the dimensions (diameter) of the sieves in $(\mathrm{mm})$ and on the ordinate the cumulative percentages of rejects or sieves.Figure 3 shows the results of the particle size analysis of the sand used.

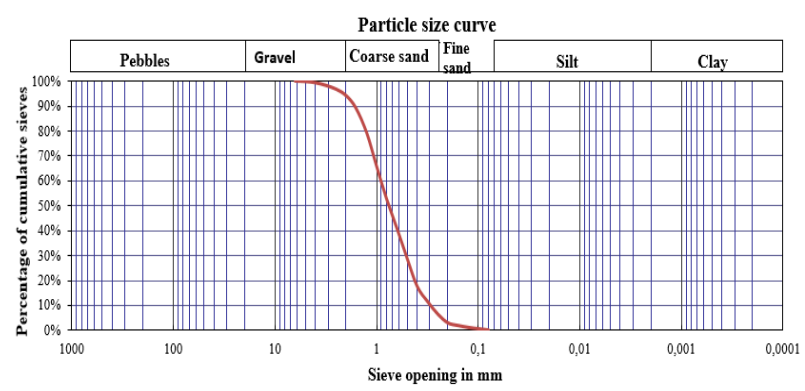

Figure 3: Particle size curve of the sand used

The fineness modulus is an important characteristic especially with regard to sands. Good concrete sand has a fineness modulus between 2.2 and 2.8. The sand used has a fineness modulus of 2.7.The sand used has a fineness modulus of between 2.2 and 2.8.Therefore, the type of sand used is preferred with satisfactory workability and good resistance with limited risks of segregation. The sand has a granulometry of which the fine elements are neither in excess nor in very small proportion. If the grains of sand are too large, the plasticity of the mixture is insufficient and makes placement difficult.

\section{Physical and mechanical properties of foamed concrete} blocks

The different values of density, porosity, compressive strength, wave speed passing through the material and Young's dynamic modulus are shown in Table 2, respectively.

Table 2: Some values of the physical and mechanical properties of

\begin{tabular}{llllll}
\multicolumn{7}{c}{ foamed concrete } \\
\hline Samples & FC1 & FC2 & FC3 & FC4 & FC5 \\
\hline Density $\left(\mathrm{kg} / \mathrm{m}^{3}\right)$ & 600 & 650 & 730 & 830 & 930 \\
$\begin{array}{l}\text { Porosity (\%) } \\
\begin{array}{l}\text { Compressive } \\
\text { strength (MPa) }\end{array}\end{array}$ & 12.36 & 69.79 & 65.79 & 60.58 & 55.60 \\
$\begin{array}{l}\text { Wave speed (m/s) } \\
\begin{array}{l}\text { Young dynamic } \\
\text { modulus (GPa) }\end{array}\end{array}$ & 1477.5 & 1556.5 & 1666 & 1776.5 & 1923 \\
\hline
\end{tabular}

\section{Porosity}

We could not experimentally determine the porosity accessible to water or open porosity and the closed porosity because the densities of the materials used are low. During the experiment, all of the samples were floating in water. This is due to the fact that the samples tested all have densities of less than $1000 \mathrm{~kg} / \mathrm{m}^{3}$.This observation was also made by N. Vinith Kumar, 2018 [13] et J. Åstrand et al[3].Foamed concretes absorb a lot of water due to their high porosity. However, they have the ability to very quickly lose this water again, which gives them properties of hygrometric regulator. Thus, we have instead determined the total porosity using the pycnometer which measures the specific density of the samples.

Figure 4 gives the average values of total porosities of the different samples. A comparison of the measured values was made with those obtained by M. A. O. Mydin, 2010 [14] and She Wei and al, 2013 [15].

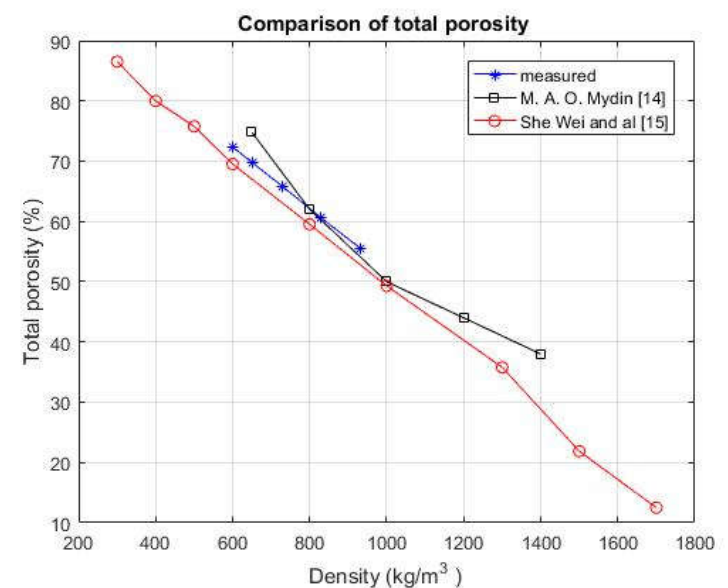

Figure 4: Evolution of the total porosity measured and that of the literature compared as a function of the density of the different samples

The results show that the total porosity of the foamed concrete which varies from $72.36 \%$ to $55.60 \%$ gradually decreases with the density. The addition of the foam increases the number of pores (open and closed pores) in the material, which results in high porosity of the bricks and results in easier water infiltration.We notice that the results obtained almost equal to those found by $\mathrm{M}$. A. 0 . Mydin and She Wei and al. The porosity of foamed concrete can reach $80 \%$ to $85 \%$ of the volume percentage[16-17]. 
Compressive strength

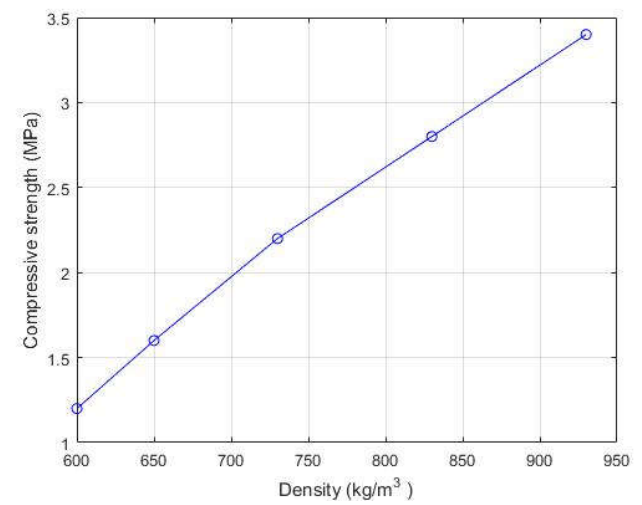

Figure 5: Evolution of the compressive strength as a function of the density of the foamed concrete

The compression tests were carried out at 28 curing days after making the bricks. The resistance values vary from 1.2 to $3.4 \mathrm{MPa}$. When the foam is added to the mortar (sand, water and cement), the number of pores in the mixture increases as the volume increases. The values of compressive strengths are proportional to the density of the concrete.

Specimens from foamed concrete with densities of 600 and $650 \mathrm{~kg} / \mathrm{m}^{3}$ have strength of 1.2 and $1.6 \mathrm{MPa}$. They can be used for filling voids in construction and for thermal insulation of roofs and ceilings. The density of 730 $\mathrm{kg} / \mathrm{m}^{3}$ with strength of $2.2 \mathrm{MPa}$ can be used for partitioning walls. The densities of 830 and $930 \mathrm{~kg} / \mathrm{m}^{3}$ have strengths of 2.8 and $3.4 \mathrm{MPa}$ and can be used for the construction of load-bearing walls. According to the standards, the resistance of the materials recommended for the construction of buildings is about $2.5 \mathrm{MPa}$ regardless of the type of habitat.

Foamed concrete being a lightweight material has a compressive strength of about 1 to $60 \mathrm{MPa}$ for a density of $300 \mathrm{~kg} / \mathrm{m}^{3}$ to $1600 \mathrm{~kg} / \mathrm{m}^{3}$ [18]. N. Vinite Kumar and al, 2018[13] found that the dry density of foamed concretes varies from $860 \mathrm{~kg} / \mathrm{m}^{3}$ to $1245 \mathrm{~kg} / \mathrm{m}^{3}$ and the compressive strength varies respectively from 2.5 to $6.5 \mathrm{MPa}$. Ben Youssef and al, 2017[9]made a study on the mechanical characterization of foamed concrete with five densities between 600 and $1400 \mathrm{~kg} / \mathrm{m}^{3}$. They found that the compressive strength of foamed concrete increases slightly between 0.65 and $4.6 \mathrm{Mpa}$ when the density of the concrete is between 600 and $1300 \mathrm{~kg} / \mathrm{m}^{3}$. But it increases much more rapidly for densities between 1300 and $1600 \mathrm{~kg} / \mathrm{m}^{3}$ (thus Rc jumps from 4.6 to $12 \mathrm{MPa}$ ). Experimental results confirmed that the mechanical properties of foamed concrete decreased with increasing macro porosity.

A. Just and B. Middendorf, 2009 [19]show that the compressive strength is proportional to the density. For a density of $700 \mathrm{~kg} / \mathrm{m}^{3}$, the increase in compressive strength is $17 \%$, and when the density raises to $1100 \mathrm{~kg} / \mathrm{m}^{3}$, the compressive strength increases by $20 \%$.The smaller the diameter of the pores, the more regularly they form. For densities of 350 to $1600 \mathrm{~kg} / \mathrm{m}^{3}$, a compressive strength is noted ranging from 0.2 to $18 \mathrm{MPa}$ [8].

Evaluation of the stiffness of the material

Ultrasonic wave propagation speed and Young's dynamic modulus

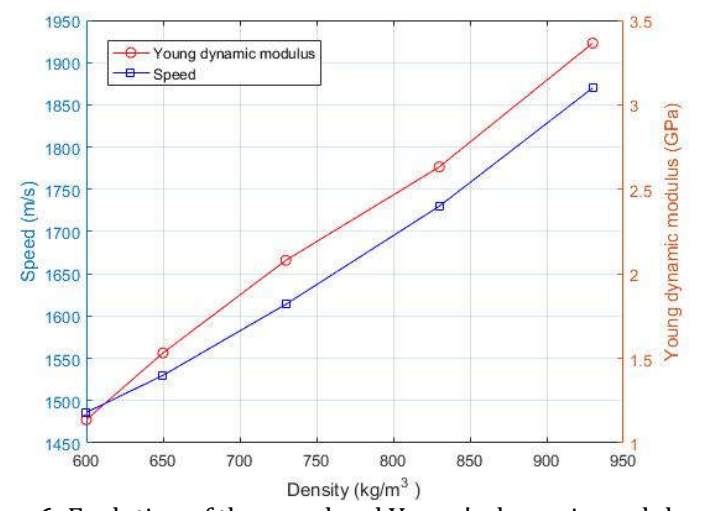

Figure 6: Evolution of the speed and Young's dynamic modulus as a function of the density of the foamed concrete

It was noticed that a gradual increase in speed as the density increases. The studied densities range from 600 to $930 \mathrm{~kg} / \mathrm{m}^{3}$ and correspond respectively to speeds ranging from 1477.5 to $1923 \mathrm{~m} / \mathrm{s}$. Ultrasonic waves pass through the material with the lowest density (contains enough pores) at a low speed. This is explained by the presence of the pores incorporated into the material. Then, the speed increases as the density of the foamed concrete increases. Thus, the speed of the ultrasonic waves of a material varies depending on the pores contained in the material.

The experimental results obtained are based on the average values of the test series performed for each density. The dynamic Young's modulus increases with increasing density. The densities of 600 to 930 $\mathrm{kg} / \mathrm{m}^{3}$ studied respectively have dynamic Young's modulus values of 1.18 to $3.1 \mathrm{GPa}$. The reduction in density also reduces the stiffness of the material. Ben Youssef et al, 2017[9]found that the Young's modulus varies between an average value of $1.2 \mathrm{GPa}$ to $13 \mathrm{GPa}$ for respective densities of 690 and $1490 \mathrm{~kg} / \mathrm{m}^{3}$. They also used a Poisson's ratio equal to 0.2 which is an average value, often used for concrete and cement materials. Thus, we can say that the results obtained are satisfactory for the material studied.

\section{Thermal properties}

The different values of thermal conductivity, thermal diffusivity, thermal effusivity and specific heat capacity are shown in Table 3, respectively.

Table3: Some values of the thermal properties of foamed concrete

\begin{tabular}{lllll}
\hline Samples & FC-650 & FC-730 & FC-830 & FC-930 \\
\hline Thermal conductivity (W/m.K) & 0.05 & 0.09 & 0.16 & 0.2 \\
Thermal diffusivity(m2/s) & $0.25310-7$ & $0.5410-7$ & $1.1610-7$ & $1.2310-7$ \\
Thermal effusivity (J/m2Ks1/2) & 291 & 387 & 455.75 & 579.75 \\
Mass heat capacity (Cp en J/kg.K) & 2819.46 & 2289.31 & 1619.38 & 1780.09 \\
\hline
\end{tabular}


Table 4 : Values of some thermo-physical and mechanical properties of foamed concrete studied with other local materials.

\begin{tabular}{|c|c|c|c|c|c|}
\hline & Matérials & $\begin{array}{l}\text { Thermal } \\
\text { conductivity } \\
(\mathrm{W} / \mathrm{m} . \mathrm{K})\end{array}$ & $\begin{array}{l}\text { Compressive } \\
\text { strength(MPa) }\end{array}$ & $\begin{array}{l}\text { Young } \\
\text { dynamic } \\
\text { modulus } \\
(\mathrm{GPa})\end{array}$ & $\begin{array}{l}\text { Density } \\
\left(\mathrm{kg} / \mathrm{m}^{3}\right)\end{array}$ \\
\hline \multirow{2}{*}{ She Wei and al [15] } & FC-1700 & 0.423 & & & 1700 \\
\hline & FC-1900 & 0.5 & & & 1900 \\
\hline Cheick Soréand al [11] & CEB & 0.6 & 1.36 & 2.9 & 1700 \\
\hline E. Ouédraogo and al [21] & Adobe & 0.556 & 2.399 & 2.548 & 1835.45 \\
\hline \multirow[t]{2}{*}{ M. G. Cuitino-Rosales and al [22] } & & 0.46 & & & 1200 \\
\hline & & 0.95 & & & 1700 \\
\hline C. Babéand al [23] & Adobe & 0.96 & & & 1700 \\
\hline \multirow{2}{*}{ M. B. Mansour and al[25] } & & 1.092 & 2.58 & & 1964 \\
\hline & & 1.469 & 3.35 & & 2106 \\
\hline Elena Olacia and al[26] & Adobe & 0.82 & 1.676 & & 1952 \\
\hline
\end{tabular}

Thermal conductivity

Figure 7 gives the average values of thermal conductivity of the different samples. A comparison of the measured values was made with those obtained by Johnny A strand, 1994[3] and She Wei and al, 2013 [15].

Figure 7 shows the evolution of thermal conductivity as a function of density. The results show that thermal conductivity increases as the density of the samples increases. The density which varies from 650 to $930 \mathrm{~kg} / \mathrm{m}^{3}$ has a thermal conductivity which corresponds respectively.

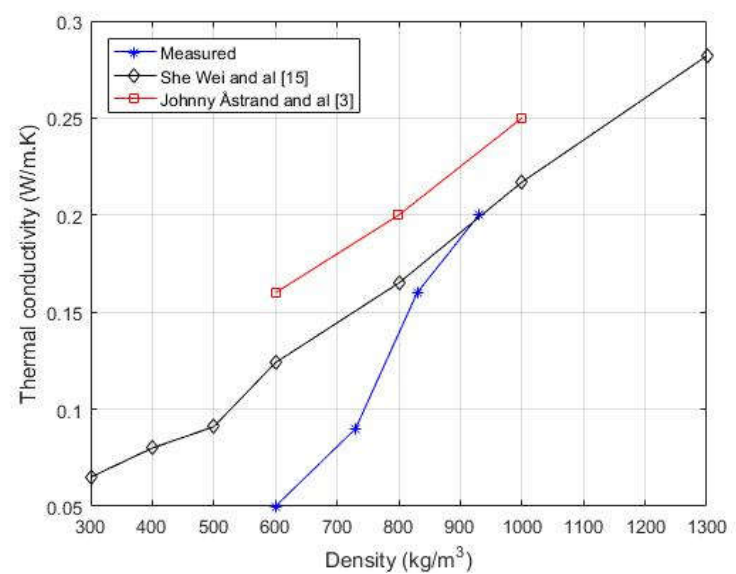

Figure 7: Evolution of thermal conductivity measured as a function of density

to 0.05 to $0.2 \mathrm{~W} / \mathrm{m}$.K. Thermal conductivity increases in proportion to density. We notice that the thermal conductivity of the three curves increases progressively as a function of the density. The results found by She Wei and al and Johnny Astrand and al are higher than those found by our measurements. This is certainly due to the quality of the different components used, the formulation and the way they are mixed. These results show that the thermal conductivities found in this paper are lower than most of the literature data. It depends on the nature of the components used.

Thermal diffusivity and thermal effusivity $\mathrm{m}^{2} / \mathrm{s}$

It was found that diffusivity and thermal effusivity change proportionally to density. The thermal diffusivity ranging from $\left(0.25 \times 10^{-7}\right.$ to $\left.1.23 \times 10^{-7} \mathrm{~m}^{2} / \mathrm{s}\right)$ and the thermal effusivity from 291 to $579.75 \mathrm{~J} / \mathrm{m}^{2}$.K.s ${ }^{1 / 2}$ correspond to the density of 650 to $930 \mathrm{~kg} / \mathrm{m}^{3}$. This gradual increase is due to the increase in the amount of foam incorporated into the mixture. Thermal diffusivity describes how quickly heat moves through a material, and thermal effusivity describes how quickly a material absorbs heat. Foamed concrete being a light material absorbs less heat and it takes longer to pass through it.
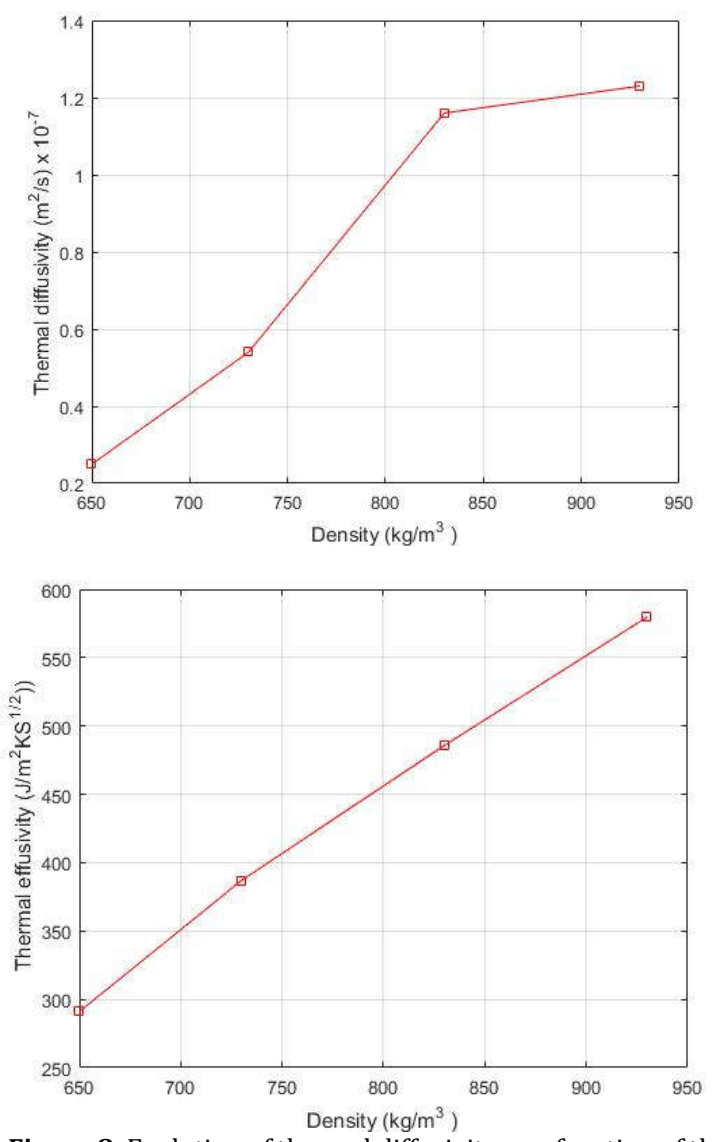

Figure 8: Evolution of thermal diffusivity as a function of the density of foamed concrete 


\section{Water content of foam concrete}

The curves below show the evolution of thermal conductivity, thermal effusivity and thermal diffusivity as a function of the water content.

\section{Effect of water content on thermal properties}

Figures 9, 10 and 11 show the evolution of thermal conductivity, thermal effusivity and thermal diffusivity as a function of the water content. The results obtained show that increasing the water content promotes an increase in thermal conductivity, thermal effusivity and thermal diffusivity of foamed concrete. This increase in the values of these various parameters as a function of the humidity level is due to the fact that the air from the pores contained in the material is gradually replaced by water, which has a higher thermal conductivity.

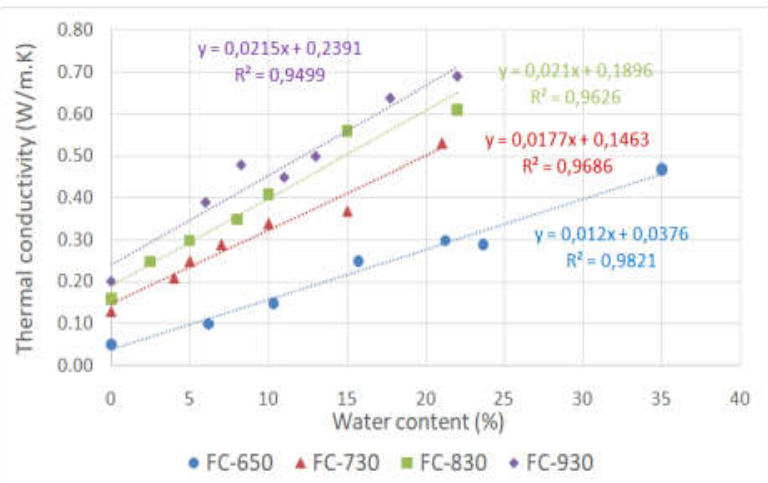

Figure 9: Thermal conductivity as a function of water content

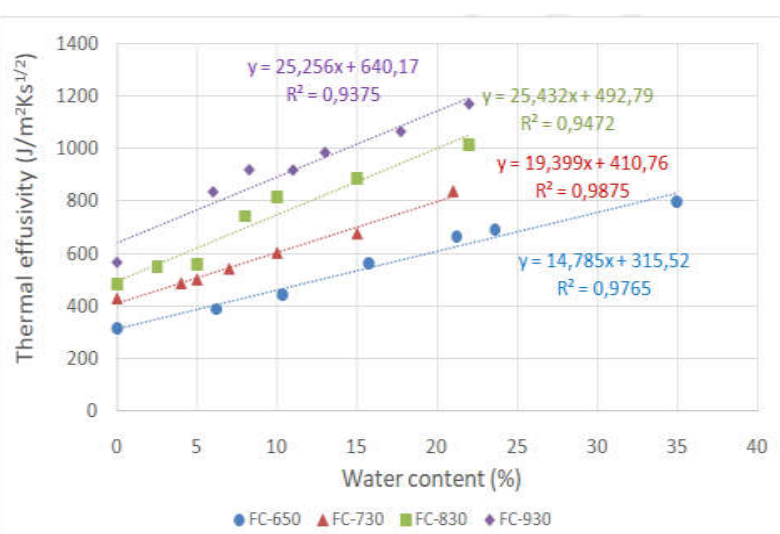

Figure 10: Thermal effusivity as a function of water content

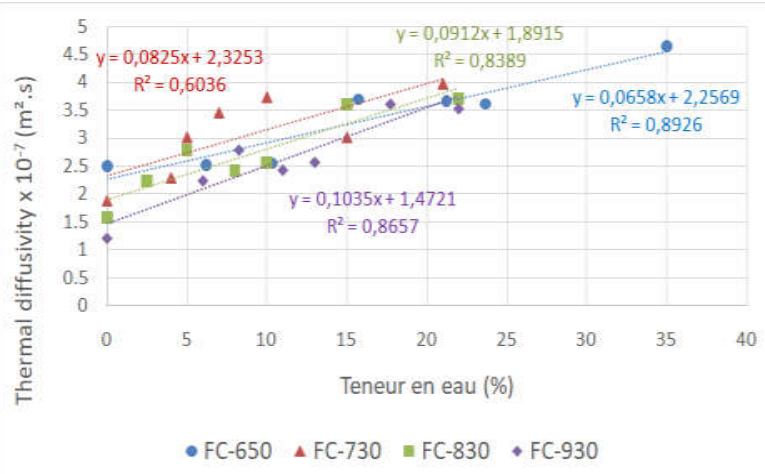

Figure 11: Thermal effusivity as a function of water content
We notice that the curves have more or less the same pace. For a density ranging from 650 to $930 \mathrm{~kg} / \mathrm{m}^{3}$, we have the maximum thermal conductivity which varies respectively from 0.47 to $0.69 \mathrm{~W} / \mathrm{m} . \mathrm{K}$ with a water content of 35 to $22 \%$. The same is true for thermal effusivity which starts from 316 to $1169 \mathrm{~J} / \mathrm{m}^{2} \mathrm{KS}^{1 / 2}$. For a density ranging from 650 to $930 \mathrm{~kg} / \mathrm{m}^{3}$, we have the maximum thermal diffusivity of the samples which varies respectively from 0.249 to $0.121 \mathrm{~m}^{2} / \mathrm{s}$. P. Nshimiyimana and al, 2020 [20] did similar work on the compressed earth block (CEB). They also observed an increase in the values of the physicochemical parameters, due to the presence of water in the materials.

\section{Comparison of properties}

Figure 12 shows an evolution of the thermal conductivity curve as a function of the density of foamed concrete, CEB and adobe. We notice that the thermal conductivity of foamed concrete $0.2 \mathrm{~W} / \mathrm{m} . \mathrm{K}$ is lower than that of other materials (CEB, and adobe). She Wei and al, 2013[15] found thermal conductivity values of $0.423 \mathrm{~W} / \mathrm{m} . \mathrm{K}$ and 0.5 $\mathrm{W} / \mathrm{m} . \mathrm{K}$ with densities of 1700 and $1900 \mathrm{~kg} / \mathrm{m}^{3}$, respectively. The thermal conductivity values of foamed concrete are lower than those of the compared materials. M. O. BOFFOUE and al, 2015 [24] worked on the influence of the cement content of the thermo mechanical properties of compressed and stabilized clay blocks. They found a thermal conductivity of $0.91 \mathrm{~W} / \mathrm{m} . \mathrm{K}$ for CEB without mixing with the cement. We notice that for a given density, the authors announce different values of thermal conductivity. This is due to variations in the physicochemical properties of the material sampled.

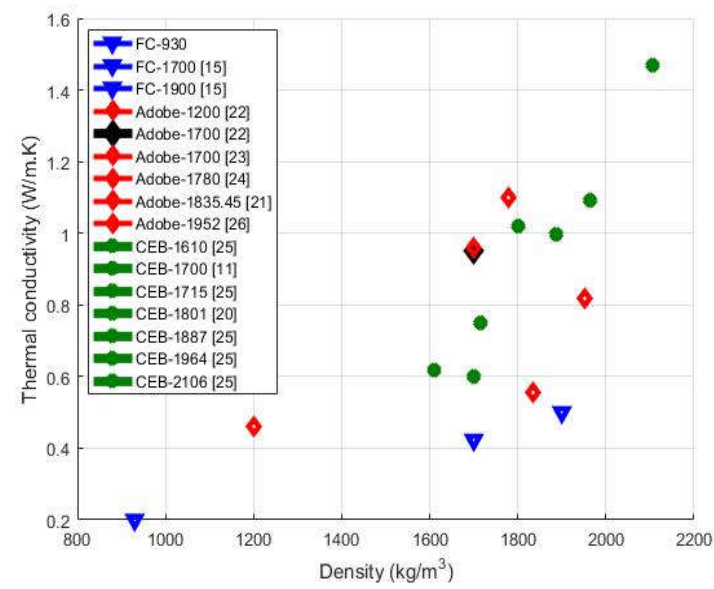

Figure 12: Comparison of thermal conductivity of foamed concrete, CEB and adobe as a function of density

Figure 13 also show a change in the curve of compressive strength as a function of the density of foamed concrete, CEB and adobe. We notice that the value of the compressive strength (3.4 MPa) of foamed concrete is higher than those of CEB and adobe without adding d 'other components. Foamed concrete also exhibits acceptable mechanical properties for the construction of buildings. The average compressive strength of an earth brick can vary from 2 to 4 $\mathrm{MPa}[27-28]$. We notice that the foamed concrete presents values lower than those of the compared materials for the thermal conductivity and higher for those of the mechanical properties. 


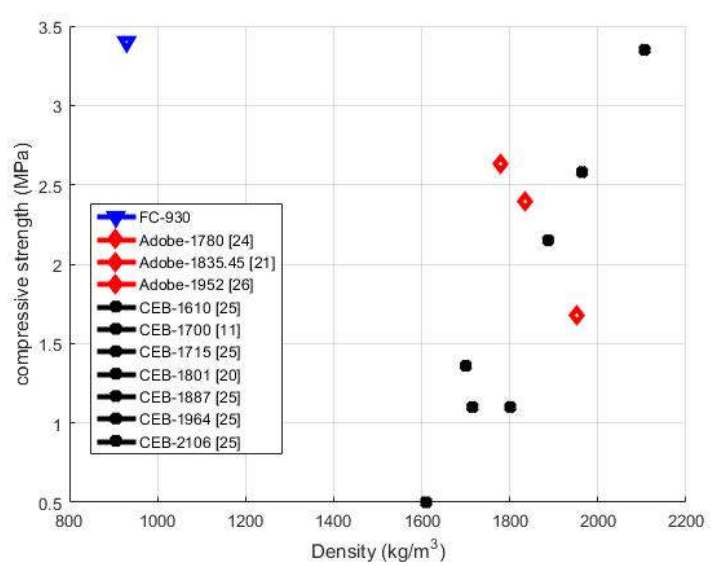

Figure 13: Some values of the compressive strength of foamed concrete, CEB and adobe as a function of density

Foamed concrete, being a light material, has poorer mechanical properties than that of conventional concrete. On the other hand, this material has very good thermal properties for building constructions. With ordinary concrete being used much more in Africa, foamed concrete is still a less used material. The use of this material will be very useful in bioclimatic constructions in hot and dry climates like Burkina Faso. This will reduce the energy bill for achieving thermal comfort.

\section{Conclusions}

This work presents the results of a series of experimental studies carried out to obtain thermal, mechanical and physical properties of foamed concrete. Mechanical properties such as compressive strength and dynamic Young's modulus lead to higher values than local materials, such as pure BTC and adobe. Thermal properties such as conductivity, diffusivity and effusivity are parameters whose values remain low regardless of the increase in density of the material, thus showing exceptional insulating properties. Regarding the variation in the hygrothermal properties of the material, there is an increase in conductivity, diffusivity and effusivity depending on the density of the material and its water content. Thus, the foamed concrete of $930 \mathrm{~kg} / \mathrm{m}^{3}$ has both mechanical and physical characteristics acceptable for certain civil engineering works and good thermal properties. The results obtained are comparable to those in the literature. It emerges from this study that foamed concrete has less advantageous mechanical properties than conventional concrete, but on the other hand, has very good thermal properties, hence a good insulating material in the construction of buildings.

\section{Acknowledgements:}

Institute for Research on Ceramics (IRCER), Limoge France which allowed us to obtain the material.

Institut 2IE, Eco-materials and Sustainable Habitat Laboratory (LEMHaD) which allowed us to test samples ISP, Uppsala University, Sweden, for its support of the BUF01 project

\section{References}

1. Ali J. Hamad, Materials, Production, Properties and Application of Aerated Lightweight Concrete: Review, Int. J. Mater. Sci. Eng., 2014, 2(2), 152-157.
2. M. Kozlowski and M. Kadela, Mechanical Characterization of Lightweight Foamed Concrete, Adv. Mater. Sci. Eng., 2018, 18.

3. Johnny Åstrand, Linda Bessadi, Eric Johansson, Saadia Laïd, Hocine Teggour and Nadjia Toumi, Materiaux thermiquement isolants Beton moussé: Panneaux en laine de bois, Universite de Lund Suede, 1994, 113.

4. Eva Namsone, Genadijs Šahmenko, and Aleksandrs Korjakins, Durability Properties of High Performance Foamed Concrete, in Elsevier, Science Direct, vol. 172, 2017, 760-767.

5. K. Ramamurthy, E. K. Kunhanandan Nambiar, and Indu Siva Ranjani Gandhi, A classification of studies on properties of foam concrete, Cement and concrete composites, 2009, 31 (6), 388-396.

6. Y. H. Mugahed Amran, Nima Farzadnia, and A. A. Abang Ali, Properties and applications of foamed concrete; A review, Constr. Build. Mater., 2015, 101, 990-1005.

7. Algurnon Steve Van Rooyen, Structural lightweight aerated concrete, Engineering in the Faculty of Engineering at Stellenbosch University, 2013, 102.

8. M. D. Jalal, Aftab Tanveer, K. Jagdeesh, and Ahmed Furqan, Foam Concrete. International Journal of Civil Engineering Research, 2017, 8(1), 1-14.

9. Marwa Ben Youssef, Karim Miled, and Jamel Néji, Mechanical properties of non-autoclaved foam concrete: analytical models vs . experimental data, Eur. J. Environ. Civ. Eng., 2017, 8189, 1-9.

10. B. Madhusudana Reddy and B. Veni, An experimental investigation on light weight foam cement blocks with quarrydust replacement for fine aggregate, Int. J. Eng. Reaseach Dev., 2017, 4(4), 1211-1217.

11. Seick Omar Sore, Adamah Messan, Elodie Prud'homme, Gilles Escadeillas, and François Tsobnang, Stabilization of compressed earth blocks (CEBs) by geopolymer binder based on local materials from Burkina Faso, Constr. Build. Mater., 2018, 165, 333-345.

12. Layal Chahwane, Valorisation de l'inertie thermique pour la performance énergétique des bâtiments, Thesis, Université de Grenoble, 2012, 223.

13. N. Vinith Kumar, C. Arunkumar, and S. Srinivasa Senthil, Experimental Study on Mechanical and Thermal Behavior of Foamed Concrete, Sci. DirectMaterials Today Proc., 2018, 5(2), 8753-8760.

14. M. Azree Othuman Mydin, Lightweight Foamed Concrete (LFC) thermal and mechanical properties at elevated temperatures and its application to composite walling system content, Thesis, University of Manchester 2010, 281.

15. She Wei, Chen Yiqiang, Zhang Yunsheng, and M. R. Jones, Characterization and simulation of microstructure and thermal properties of foamed concrete, Constr. Build. Mater., 2013, 47, 1278-1291.

16. N. Narayanan and K. Ramamurthy, Structure and properties of aerated concrete: a review, ELSEVIER, 2000, vol. 22, pp. 321-329.

17. E. P. Kearsley and P. J. Wainwright, Porosity and permeability of foamed concrete, Cement and concrete Research, 2001,31, 805-812.

18. Nooraini Mohd Zahari, Ismail Abdul Rahman, Ahmad Mujahid and Ahmad Zaidi, Foamed Concrete: Potential Application in Thermal Insulation, Malaysian Tech. Univ. Conf. Eng. Technol., 2009, 47-52.

19. A. Just and B. Middendorf, Microstructure of high-strength foam concrete, Mater. Charact., 2008, 60(7), 741-748.

20. Philbert Nshimiyimana, Adamah Messan, and Luc Courard, Physico-mechanical and hygro-thermal properties of compressed earth blocks stabilized with industrial and agro by-product binders, Materials (Basel)., 2020, 13(17), 1-17.

21. Emmanuel Ouedraogo, Ousmane Coulibaly, Abdoulaye Ouedraogo, and Adamah Messan, Caractérisation mécanique et thermophysique des blocs de terre comprimée stabilisée au papier ( cellulose ) et / ou au ciment, J. Mater. Eng. Struct. 2, 2015, 2, 68-76.

22. Maria Guadalupe Cuitiño-Rosales, Rodolfo Rotondaro, and Alfredo Esteves, Comparative analysis of thermal aspects 
and mechanical resistance of building materials and elements with earth, Revista de Arquitectura, 2020, 22(1), 138-151.

23. Colbert Babé, Dieudonné Kaoga Kidmo, Ahmat Tom, Rachel Raïssa Ngono Mvondo, Raphaël Belinga Essama Boum, and Noël Djongyang, Thermomechanical characterization and durability of adobes reinforced with millet waste fibers (sorghum bicolor), Case Stud. Constr. Mater., 2020, 13, 1-13.

24. Moro Olivier Boffoue, Koffi Clément Kouadio, and Conand Honoré Kouakou, Aka Alexandre Assandé, Anne Bauscher, Bertrand Lenoir et Edjikemé Emeruwa, Influence de la teneur en ciment sur les propriétés thermomécaniques des blocs d'argile comprimée et stabilisée, Afrique science, 2015, 11(2), 35-43.

25. Mohamed Ben Mansour, Ahmed Jelidi, Amel Cherif Soukaina, and Sadok Ben Jabrallah, Optimizing thermal and mechanical performance of compressed earth blocks ( CEB ), Constr. Build. Mater., 2016, 104, 44-51.

26. Elena Olacia, Anna Laura Pisello, Vitaliano Chiodo, Susanna Maisano, Andrea Frazzica, and Luisa F. Cabeza, Sustainable adobe bricks with seagrass fibres. Mechanical and thermal properties characterization, Constr. Build. Mater., 2020, 239, 117669.

27. Tuan Anh Phung, Formulation et caractérisation d'un composite terre-fibres végétales : la bauge, Thèse, Université de Caen Normandie, 2018, 180.

28. Etienne Malbila,David Y.K Toguyeni, Saïdou Bamogo, Abdou Lawane, Jean Koulidiati, Thermophysical and Mechanical Characterization of Local Stabilized Materials Suitable for Buildings in Dry and Hot Climate, Journal of Materials Science\& Surface Ingineering, 2018,6(2), 767-772. 